\title{
ACTO DE HOMENAJE AL PROFESOR Dr. LASCAR SAVEANU
}

El Consejo Departamental de Economía, interpretando el sentimiento de gratitud de su comunidad docente hacia este hombre, quien contribuyó a fundarle, fortalecerle y engrandecerle, resolvió el día 13 de abril de 1998 (Res. CDE -062/1998) realizar un acto de homenaje a la persona y a la trayectoria académica del Profesor Dr. Lascar Saveanu, con motivo de cumplirse el 9 de julio de este año el decimoquinto aniversario de su fallecimiento. El Departamento de Economía fue beneficiario también del último legado del Profesor Dr. Lascar Saveanu al recibir en donación, y por expresa voluntad de su señora esposa, su biblioteca personal, la cual ha sido incorporada a la biblioteca especializada de Economía (Res. CDE - 089/ 1998).

Dichas resoluciones del Consejo Departamental encuentran su fundamento en el convencimiento que las instituciones representan el accionar pasado y presente de sus integrantes, unidos en la consecución de objetivos compartidos. El Profesor Dr. Lascar Saveanu, a quien está dedicado este número especial de "Estudios Económicos", fue un destacadísimo protagonista de la etapa fundacional del Departamento de Economía de la Universidad Nacional del Sur, al que consagró íntegramente su vida profesional y realizó un aporte decisivo en sus primeros quince años de existencia. El pensamiento humanista, plural y europeo del Profesor Saveanu caló hondo hasta en las raíces mismas de esta institución.

Profesor de Historia económica, Historia Económica Contemporánea y Fluctuaciones Económicas legó a varias generaciones de alumnos el deseo de aprender e investigar los por qué en la búsqueda permanente de la verdad. La formación de recursos humanos de la mayor jerarquía académica fue una de sus preocupaciones constantes, en particular, en una unidad de docencia e investigación por entonces en su etapa constitutiva.

Mg. Raúl Oscar Dichiara

Director Decano Departamento de Economía 